\title{
Temporal trends of molecular markers associated with artemether-lumefantrine tolerance/resistance in Bagamoyo district, Tanzania
}

Maja Malmberg ${ }^{1 *}$, Billy Ngasala ${ }^{2}$, Pedro E Ferreira ${ }^{1,3}$, Erik Larsson ${ }^{1}$, Irina Jovel ${ }^{1,4}$, Angelica Hjalmarsson?', Max Petzold ${ }^{5}$, Zul Premji ${ }^{2}$, José P Gil ${ }^{3,6,7}$, Anders Björkman ${ }^{1}$ and Andreas Mårtensson ${ }^{1,8}$

\begin{abstract}
Background: Development and spread of Plasmodium falciparum resistance to artemisinin-based combination therapy (ACT) constitutes a major threat to recent global malaria control achievements. Surveillance of molecular markers could act as an early warning system of ACT-resistance before clinical treatment failures are apparent. The aim of this study was to analyse temporal trends of established genotypes associated with artemether-lumefantrine tolerance/resistance before and after its deployment as first-line treatment for uncomplicated malaria in Tanzania 2006.

Methods: Single nucleotide polymorphisms in the P. falciparum multidrug resistance gene 1 (pfmdr1) N86Y, Y184F, D1246Y and P. falciparum chloroquine transporter gene (pfcrt) K76T were analysed from dried blood spots collected during six consecutive studies from children with uncomplicated $P$. falciparum malaria in Fukayosi village,

Bagamoyo District, Tanzania, between 2004-2011.

Results: There was a statistically significant yearly increase of pfmdr1 N86, 184F, D1246 and pfcrt K76 between 2006-2011 from $14 \%$ to $61 \%$ (yearly $O R=1.38[95 \% \mathrm{Cl} 1.25-1.52] \mathrm{p}<0.0001), 14 \%$ to $35 \%(\mathrm{OR}=1.17[95 \% \mathrm{Cl}$ 1.07-1.30] $\mathrm{p}=0.001), 54 \%$ to $85 \%(\mathrm{OR}=1.21[95 \% \mathrm{Cl} 1.03-1.42] \mathrm{p}=0.016)$ and $49 \%$ to $85 \%(\mathrm{OR}=1.33[95 \% \mathrm{Cl}$ 1.17-1.51] $\mathrm{p}<0.0001$ ), respectively. Unlike for the pfmdr1 SNP, a significant increase of pfcrt K76 was observed already between 2004-2006, from 26\% to 49\% (OR = 1.68 [95\% Cl 1.17-2.40] $p=0.005$ ). From 2006 to 2011 the pfmdr1 NFD haplotype increased from $10 \%$ to $37 \%(\mathrm{OR}=1.25$ [95\% Cl 1.12-1.39] $\mathrm{p}<0.0001)$, whereas the YYY haplotype decreased from $31 \%$ to $6 \%(\mathrm{OR}=0.73[95 \% \mathrm{Cl} 0.56-0.98] \mathrm{p}=0.018)$. All 390 successfully analysed samples had one copy of the pfmdr1 gene.

Conclusion: The temporal selection of molecular markers associated with artemether-lumefantrine tolerance/ resistance may represent an early warning sign of impaired future drug efficacy. This calls for stringent surveillance of artemether-lumefantrine efficacy in Tanzania and emphasizes the importance of molecular surveillance as a complement to standard in vivo trials.
\end{abstract}

Keywords: Plasmodium falciparum, Malaria, pfmdr1, pfcrt, Artemether-lumefantrine, Lumefantrine, Drug resistance, Tanzania

\footnotetext{
* Correspondence: malmberg.maja@gmail.com

${ }^{1}$ Malaria Research, Department of Medicine Solna, Karolinska Institutet,

Stockholm, Sweden

Full list of author information is available at the end of the article
}

\section{Biomed Central}

(c) 2013 Malmberg et al.; licensee BioMed Central Ltd. This is an Open Access article distributed under the terms of the Creative Commons Attribution License (http://creativecommons.org/licenses/by/2.0), which permits unrestricted use, distribution, and reproduction in any medium, provided the original work is properly cited. 


\section{Background}

Modern malaria control relies primarily on sustained efficacy of artemisinin-based combination therapy (ACT). Reports of artemisinin tolerant/resistant Plasmodium falciparum from Southeast Asia [1-3] constitute, therefore, a major threat to recent global malaria control achievements. Within the African continent there has to date been no clear evidence of artemisinin resistance, but an increased parasite positivity rate on day 1 after initiation of ACT treatment has been reported from Kenya [4].

ACT is a combination of an artemisinin derivative, which rapidly reduces the parasite load, and a longacting partner drug that kills the remaining parasites and suggestively protects the artemisinin component from resistance development. During clearance of the long-acting partner drug re-infecting parasites are exposed to slowly declining drug concentrations during several weeks. This phenomenon, which is of particular importance in high transmission areas, may be the starting point for development of tolerance/resistance towards the long-acting partner drug. This could initially result in a shorter post-treatment prophylactic effect and eventually reduce the ACT to an artemisinin derivative monotherapy.

The most commonly used ACT in Africa is artemetherlumefantrine. It has been deployed as first-line treatment for uncomplicated malaria in Tanzania since 2006. Artemether-lumefantrine has shown to be highly efficacious with PCR-corrected cure rates exceeding 95\% [5-7]. However, artemether-lumefantrine has been associated with selection of single nucleotide polymorphisms (SNPs) in genes associated with anti-malarial drug resistance among re-infections, as compared with baseline parasite characteristics [8-10]. The main SNPs are P. falciparum multidrug resistance gene 1 (pfmdr1) N86, 184F and D1246 [8,9] and the P. falciparum chloroquine transporter gene (pfcrt) K76 allele [10]. This highlights the need of close surveillance of molecular markers as an early warning system of development and spread of anti-malarial drug resistance and an important tool for insights into drug resistance development.

The aim of this study was to assess temporal trends of molecular markers associated with anti-malarial drug resistance in a rural Tanzanian village before and after wide scale deployment of artemether-lumefantrine as first-line treatment of uncomplicated $P$. falciparum malaria.

\section{Methods}

\section{Study area}

The studies were conducted in Fukayosi village, Bagamoyo District, Coast region, Tanzania. Fukayosi dispensary serves a population of approximately 7,000 people. The catchment area is primarily rural. Malaria transmission is high and occurs throughout the year with peaks related to the rainy seasons in May to July (long rains) and December to January (short rains). Plasmodium falciparum is the predominant malaria species and Anopheles gambiae complex the main vector. In 2004, sulphadoxinepyrimethamine was first-line treatment and amodiaquine second-line treatment for uncomplicated malaria. Since November 2006 artemether-lumefantrine has been the first-line treatment.

\section{Study design and population}

Study 1 was a two-arm (artemether-lumefantrine versus sulphadoxine-pyrimethamine) efficacy trial conducted in 2004 [6]. Study 2 was an artemether-lumefantrine pharmacokinetic and pharmacodynamics study performed in 2006 [11]. Study 3 was a two-arm (efficacy versus effectiveness) artemether-lumefantrine clinical trial conducted in 2007 [7]. Study 4, Study 5 and Study 6 represent pretreatment blood samplings done in 2008, 2010 and 2011, respectively (unpublished data). In total, 777 patients were included in the present analysis.

The study population consisted of children $\leq 10$ years with symptomatic, uncomplicated, microscopy confirmed $P$. falciparum infection. Detailed inclusion and exclusion criteria for Studies 1 to 3 have been reported elsewhere $[5,7,11]$. A brief descriptive summary of study population is presented in Table 1.

\section{Biological material}

Blood spots were collected on filter paper (Whatman 3 $\mathrm{MM})$ just prior to initiation of anti-malarial treatment, dried and put in individual zipper plastic bags. Thereafter, they were transported to Karolinska Institutet, Sweden, for molecular analysis.

\section{Molecular analysis \\ DNA extraction and analysis}

Genomic DNA was extracted from the dried blood spots using the BloodPrep ${ }^{\text {TM }}$ Chemistry on an ABI PRISM ${ }^{\circledR}$ 6100 (Applied Biosystems ${ }^{\mathrm{TM}}$, Fresno, CA, USA) according to the manufacturer's instructions, and analysed by PCR for the presence of different genetic markers associated with anti-malarial drug resistance.

\section{Genotyping of pfmdr1 and pfcrt}

Pfmdr1 N86Y and pfcrt K76T were genotyped using PCR-RFLP according to previously described protocol [12]. Restriction fragments were loaded on $2 \%$ agarose gels containing $0.1 \mu \mathrm{g} / \mathrm{ml}$ ethidium bromide, separated by electrophoresis and visualized under UV transillumination (GelDoc System, Biorad, Hercules, CA, USA). Pfmdr1 Y184F was analysed by pyrosequencing in Study 1 [13], sequencing in Studies 2 and 3 [14] and PCR- 
Table 1 Base line characteristics of the study population

\begin{tabular}{|c|c|c|c|c|c|c|}
\hline & Study 1 & Study 2 & Study 3 & Study 4 & Study 5 & Study 6 \\
\hline Year & 2004 & 2006 & 2007 & 2008 & 2010 & 2011 \\
\hline Study period & May & Jun & May - Nov & Aug-Oct & $\begin{array}{l}\text { Oct-Dec + Jan } \\
2011\end{array}$ & Apr-Jun \\
\hline Patients included (n) & 106 & 50 & 258 & 200 & 33 & 130 \\
\hline Sex, female patients (\%) & 51 & 62 & 54 & 49 & 49 & 50 \\
\hline Age, months, median (range) & $31(6-135)$ & $48(12-119)$ & $31(4-60)$ & $36(2-124)$ & N.D & $60(12-120)$ \\
\hline Weight, kg, median (range) & $12(6-33)$ & $13(8-30)$ & $12(5-21)$ & $12(5-33)$ & $13(6-29)$ & $15(8-32)$ \\
\hline Parasites $/ \mu \mathrm{L}$, geometric mean (range) & $\begin{array}{l}21,595(2,000- \\
160,000)\end{array}$ & $\begin{array}{l}36,885(2,120- \\
200,400)\end{array}$ & $\begin{array}{c}43,259(2,700- \\
192,320)\end{array}$ & $\begin{array}{l}17,531(2,000- \\
192,000)\end{array}$ & $\begin{array}{c}18,537(2,400- \\
185,120)\end{array}$ & $\begin{array}{c}10,198(1,080- \\
112,800)\end{array}$ \\
\hline $\begin{array}{l}\text { Slide positivity rate, microscopy } \\
\text { positive/screened (\%) }\end{array}$ & $175 / 434(40 \%)$ & 148/277 (53\%) & $718 / 1403(51 \%)$ & $473 / 745(63 \%)$ & 99/588 (17\%) & $599 / 1002(60 \%)$ \\
\hline
\end{tabular}

RFLP in Studies 4, 5 and 6. Pfmdr1 D1246Y was analysed by PCR-RFLP in Studies 1, 4, 5 and 6 [13], pyrosequencing in Study 2 and sequencing in Study 3 [15]. To maintain consistency in the analysis of mixed infections, samples from Study 2 were analysed by pyrosequencing ( $p f m d r 1$ D1246Y, pfmdr1 Y184F), together with a dilution series of mixed DNA in different proportions from the clones 7G8 (pfmdr1 1246Y, pfmdr1 184F carrier) and 3D7 (pfmdr1 D1246, pfmdr1 Y184 carrier). Samples with more than $10 \%$ of each allele at a particular locus were defined as mixed infections. The cut off values were used to re-assess the data from Study 1 [10] to ensure consistency.

Sequencing was done by Macrogen Inc (Seoul, Korea), Sequencher ${ }^{\mathrm{TM}}$ software version 4.6 (Gene Codes Corporation, Ann Arbor, MI, USA) was used to analyse the sequences with $3 \mathrm{D} 7$ as the $p f m d r 1$ reference sequence (PFE1150w, Gene ID 813045 at NCBI RefSeq, National Center for Biotechnology Information Reference Sequence). The PCR success rates for $p f m d r 1$ N86Y, Y184F, D1246Y and pfcrt K76T were 97\% (752/ 777), 96\% (749/777), 95\% (740/777) and 96\% (749/ 777), respectively.

\section{pfmdr1 copy number variation}

In Study 1, 2, 3 and partly Study 4, pfmdr 1 copy number was assessed using Taqman ${ }^{\circledR}$ based real-time PCR (ABI Prism $\left.^{\circledR} 7000\right)$ [16]. $\beta$-tubulin was used as one copy endogenous control. The clones 3D7, K1, D10, all with one copy of $p f m d r 1$, were used as calibrators. Dd2 and FCB were used as multi-copy controls. All samples were run in triplicates. PCR success rates were 84\% (89/106), 96\% (48/50), 81\% (208/258) and 90\% (45/50) for Studies 1, 2, 3 and 4 , respectively.

\section{Ethical considerations}

Before enrolment, written informed consent was obtained from parents/legal guardians of the children. The studies were approved by the National Institute for Medical Research, Tanzania and Karolinska Institutet
Ethical Review Board or the Regional Ethics Committee, Stockholm, Sweden. Studies 2 and 3 were registered with identifier NCT00336375 [17] and ISRCTN69189899 [18], respectively.

\section{Statistical analysis}

For prevalence analysis of individual SNPs, mixed infections (both alleles present at a particular locus) were analysed together with the polymorphism not associated with lumefantrine tolerance/resistance, i.e., pfmdr1 86Y, Y184, 1246Y and pfcrt $76 \mathrm{~T}$. For haplotype analysis, minority haplotypes $(\leq 5 \%)$ and infections that were mixed at two or more loci were excluded. Infections that were mixed at only one locus were analysed as having both haplotypes. The combined pfmdr1 and pfcrt haplotype was made based on the $p f m d r 1$ haplotypes.

Logistic regression with year included as a continuous covariate was used to estimate the yearly changes in prevalence. The presented odds ratios (OR) with corresponding 95\% confidence intervals (CI) represent the relative change per year. The 2006 study, conducted in June, i.e., just prior to artemetherlumefantrine deployment, was used as baseline for trend analysis. Statistical significances were confirmed using non-parametric trend test. STATA v. 12 was used for all analysis, figures were made in SigmaPlot ${ }^{\circledR} 11$, p-values were estimated using bootstrapping (100 repeats) and a p-value $<0.05$ was considered statistically significant.

\section{Results}

\section{Description of study population}

A total of 777 patients were included in the analysis. The details of the study population are presented in Table 1 . The blood slide positivity rate for Study 5 was lower (17\%) compared with the mean all other studies combined (53\%). 
Temporal trends in the prevalence of SNPs in pfmdr1 and pfcrt SNPs

There was a statistically significant increase of pfmdr 1 N86, 184F and D1246 over the time period 2006 to 2011 from $14 \%$ to $61 \%$ (yearly OR $=1.38$ [95\% CI $1.25-1.52]$ $\mathrm{p}<0.0001), 14 \%$ to $35 \%(\mathrm{OR}=1.17$ [95\% CI 1.07-1.30] $\mathrm{p}=0.001)$ and $54 \%$ to $85 \%(\mathrm{OR}=1.21$ [95\% CI 1.031.42] $\mathrm{p}=0.016$ ), respectively (Figure 1 , Table 2 ). No significant yearly change was observed between 2004 and 2006. During the same time period there was a significant increase of pfcrt K76 from $49 \%$ pre-AL to $85 \%$ $(\mathrm{OR}=1.33$ [95\% CI 1.17-1.51] $\mathrm{p}<0.0001)$. However, a significant increase of pfcrt K76 was observed already between 2004-2006, from $26 \%$ to $49 \%$ (OR = 1.68 [95\% CI $1.17-2.40] \mathrm{p}=0.005$ ).
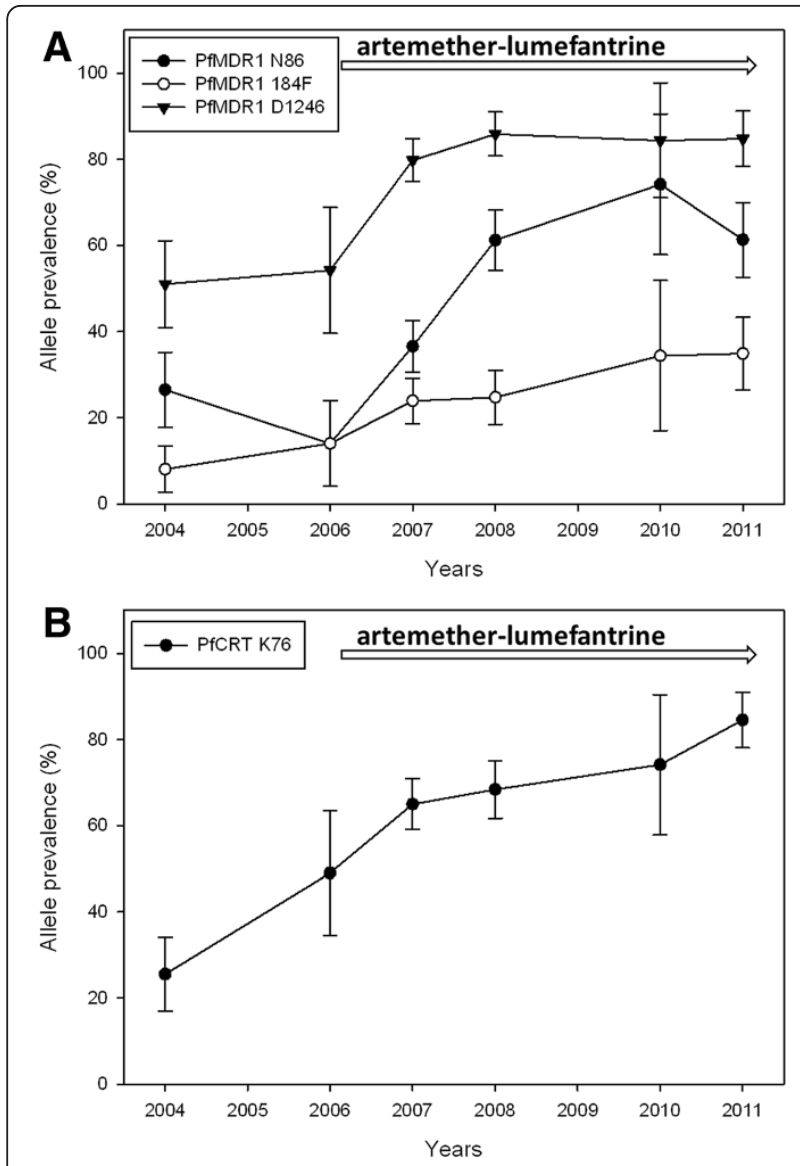

Figure 1 Temporal trends of PfMDR1 N86Y, Y184F, D1246Y and PfCRT K76T. Temporal trends (means and 95\% confidence intervals) of A) PfMDR1 N86, 184F, D1246 and B) PfCRT K76 during 2004-2011 in Fukayosi village, Bagamoyo District, Tanzania. Mixed infections (both alleles present at a particular locus) were analysed together with the polymorphism not associated with lumefantrine tolerance/ resistance, i.e., PfMDR1 86Y, Y184, 1246Y and PfCRT 76 T. The arrow indicates when artemether-lumefantrine has been first-line treatment.

\section{pfmdr1 haplotypes}

The prevalences of $p f m d r 1$ haplotypes at codon N86Y, Y184F, D1246Y during 2004-2011 are presented in Figure 2. There was a statistically significant increase of NFD haplotype between 2006-2011 from 10\% to 37\% $(\mathrm{OR}=1.25$ [95\% CI 1.12-1.39] $\mathrm{p}<0.0001)$. During the same period the NYD showed a trend of increase from $18 \%$ to $35 \%(\mathrm{OR}=1.10$ [95\% CI 0.98-1.23] $\mathrm{p}=0.098)$. The YYD and YYY haplotypes decreased significantly 2006 to 2011 from $44 \%$ to $21 \%$ (OR $=0.79$ [95\% CI 0.68 $0.90] \mathrm{p}<0.0001)$ and $31 \%$ to $6 \%(\mathrm{OR}=0.73[95 \% \mathrm{CI}$ 0.56-0.98] $\mathrm{p}=0.018)$, respectively.

\section{The combined pfmdr1 and pfcrt haplotypes}

There was a statistically significant increase of the NFD + K haplotype from $12 \%$ to $36 \%$ (OR 1.27 [95\% CI 1.12-1.45] $\mathrm{p}<0.0001)$ between 2006-2011. During the same period the NYD + K haplotype increased from $7 \%$ to $28 \%$ (OR 1.10 [95\% CI 0.97-1.25] p=0.127). Between 2006 and 2011 there was a significant decrease of the $\mathrm{YYD}+\mathrm{K}$ and YYD + T from 29\% to 20\% (OR 0.86 [95\% CI $0.74-1.00] \mathrm{p}=0.041$ ) and $17 \%$ to $0 \%$ (OR 0.59 [95\% CI $0.41-0.83] \mathrm{p}=0.003)$, respectively. During the same time period there was a decrease in prevalence of $\mathrm{YYY}+\mathrm{T}$ from $19 \%$ to $2 \%$ (OR 0.63 [95\% CI 0.39-1.00] $\mathrm{p}=0.05$ ). This decrease was statistically significant by nonparametric trend test $(\mathrm{p}=0.003)$ (Table 3$)$.

\section{pfmdr1 copy number variation}

All 390 successfully analysed samples had one copy of the $p f m d r 1$ gene.

\section{Discussion}

This study provides evidence for a continuous selection of molecular markers associated with artemetherlumefantrine tolerance/resistance in the local $P$. falciparum population in Fukayosi village, Bagamoyo district, Tanzania, occurring after the introduction of this ACT as first-line treatment for uncomplicated malaria in 2006.

The results support previous observations of pfmdr1 N86 selection in Gabon, Kenya and Mozambique [19-21] as well as selection of both pfmdr1 N86 and 184F in Korogwe, Tanzania [22], and the pfmdr1 N86, 184F, D1246 haplotype in Mozambique [23] following wide scale deployment of artemether-lumefantrine. However, the present report adds substantially to the evidence base being more comprehensive both with regards to number of patients and genetic markers analysed, and importantly with a longer duration of follow-up.

Interestingly the selection of pfcrt K76 started already prior to the introduction of artemether-lumefantrine in Bagamoyo district. This probably represents an effect of 
Table 2 Prevalences of pfmdr1 and pfcrt SNPs in Fukayosi village, Bagamoyo District, Tanzania, from 2004-2011

\begin{tabular}{|c|c|c|c|c|c|c|c|c|c|c|c|c|c|}
\hline \multirow[t]{2}{*}{ Gene } & \multirow[t]{2}{*}{ Mutation } & \multicolumn{2}{|c|}{$\begin{array}{c}\text { Study } 1 \\
2004\end{array}$} & \multicolumn{2}{|c|}{$\begin{array}{c}\text { Study } 2 \\
2006\end{array}$} & \multicolumn{2}{|c|}{$\begin{array}{c}\text { Study } 3 \\
2007\end{array}$} & \multicolumn{2}{|c|}{$\begin{array}{c}\text { Study } 4 \\
2008\end{array}$} & \multicolumn{2}{|c|}{$\begin{array}{c}\text { Study } 5 \\
2010\end{array}$} & \multicolumn{2}{|c|}{$\begin{array}{c}\text { Study } 6 \\
2011\end{array}$} \\
\hline & & $\mathrm{n}=$ & (\%) & $\mathrm{n}=$ & (\%) & $n=$ & (\%) & $n=$ & $(\%)$ & $n=$ & $(\%)$ & $\mathrm{n}=$ & $(\%)$ \\
\hline \multirow[t]{9}{*}{ pfmdr1 } & N86 & 27 & 26.5 & 7 & 14 & 94 & 36.6 & 115 & 61.1 & 23 & 74.2 & 76 & 61.3 \\
\hline & mix-86 & 30 & 29.4 & 19 & 38 & 71 & 27.6 & 27 & 14.4 & 3 & 9.7 & 20 & 16.1 \\
\hline & $86 Y$ & 45 & 44.1 & 24 & 48 & 92 & 35.8 & 46 & 24.5 & 5 & 16.1 & 28 & 22.6 \\
\hline & $184 \mathrm{~F}$ & 8 & 8 & 7 & 14 & 61 & 23.9 & 46 & 24.7 & 10 & 32.3 & 44 & 34.9 \\
\hline & $\operatorname{mix}-184$ & 17 & 17 & 6 & 12 & 30 & 11.8 & 23 & 12.4 & 8 & 25.8 & 15 & 11.9 \\
\hline & Y184 & 75 & 75 & 37 & 74 & 164 & 64.3 & 117 & 62.9 & 13 & 41.9 & 67 & 53.2 \\
\hline & D1246 & 50 & 51 & 26 & 54.2 & 202 & 79.8 & 158 & 85.9 & 27 & 84.4 & 106 & 84.8 \\
\hline & mix-1246 & 24 & 24.5 & 14 & 29.2 & 20 & 7.9 & 15 & 8.1 & 4 & 12.5 & 14 & 11.2 \\
\hline & $1246 \mathrm{Y}$ & 24 & 24.5 & 8 & 16.7 & 31 & 12.3 & 11 & 6 & 1 & 3.1 & 5 & 4 \\
\hline \multirow[t]{3}{*}{ pfert } & K76 & 26 & 25.5 & 24 & 49 & 167 & 65 & 128 & 68.4 & 23 & 74.2 & 104 & 84.6 \\
\hline & mix-76 & 23 & 22.5 & 11 & 22.5 & 43 & 16.7 & 28 & 15 & 2 & 6.5 & 5 & 4.1 \\
\hline & $76 \mathrm{~T}$ & 53 & 52 & 14 & 28.6 & 47 & 18.3 & 31 & 16.6 & 6 & 19.4 & 14 & 11.4 \\
\hline
\end{tabular}

$\mathrm{N}=$ asparagine, $\mathrm{Y}=$ tyrosine, $\mathrm{F}=$ phenylalanine, $\mathrm{D}=$ aspartic acid, $\mathrm{mix}=$ the presence of both alleles at one loci.

the withdrawal of chloroquine as first-line treatment in 2001, consistent with observations from Malawi where withdrawal of chloroquine resulted in a fast reexpansion of a diverse chloroquine-susceptible pfcrt $\mathrm{K} 76$ population [24]. Thus, the herein observed increase in pfcrt K76 may not necessarily only be due to the introduction of artemether-lumefantrine, but could also, at least partly, be explained by the withdrawal of chloroquine and/or other factors, such as parasite fitness and transmission intensity [24-26]. Conversely, no selection of pfmdr1 N86, 184F, D1246 occurred prior to introduction of artemether-lumefantrine in the study area. The selection of these SNPs seen after 2006 is therefore unlikely driven by the withdrawal of chloroquine.

There are evidences that exposure of artemetherlumefantrine is the main contributor behind the observed selection of pfmdr1 N86, 184F, D1246 SNPs and that it plays a role also for selection of $p f c r t \mathrm{~K} 76$. These evidences include the previously reported specific lumefantrine-driven selection among re-infections during follow up after artemether-lumefantrine treatment $[9,10]$, in vitro findings [27] and a recent study conducted in Tanzania, which shows that the selection of N86, 184F and D1246 after artemether-lumefantrine

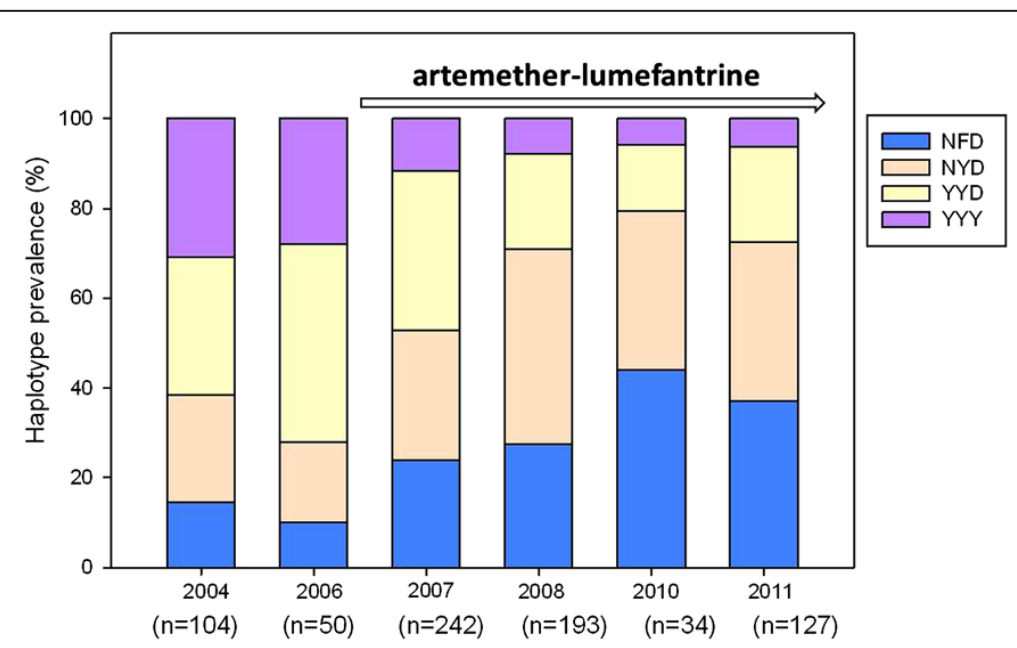

Figure 2 Temporal trends of PfMDR1 haplotypes. Prevalences of PfMDR1 haplotypes at codon N86Y, Y184F, D1246Y in Fukayosi village, Bagamoyo District, Tanzania, from 2004-2011. Minority haplotypes ( $\leq 5 \%)$ and infections that were mixed (both alleles present at a particular locus) at 2 two or more loci were excluded. Infections that were mixed at only one locus were analysed as having both haplotypes. The arrow indicates when artemether-lumefantrine has been first-line treatment for uncomplicated malaria. 
Table 3 Prevalences of the combined pfmdr1 and pfcrt haplotypes in Fukayosi village, Bagamoyo district, Tanzania, from 2006-2011

\begin{tabular}{|c|c|c|c|c|c|c|c|c|c|}
\hline Haplotype & 2006 & 2007 & 2008 & 2010 & 2011 & $\begin{array}{l}\text { Yearly } \\
\text { OR }\end{array}$ & $95 \% \mathrm{Cl}$ & $\begin{array}{l}\mathrm{p} \text {-value logistic } \\
\text { regression }\end{array}$ & $\begin{array}{c}\mathrm{p} \text {-value non- } \\
\text { parametric trend test }\end{array}$ \\
\hline $\mathrm{NFD}+\mathrm{K}$ & $12 \%(5 / 42)$ & $20 \%(46 / 234)$ & $21 \%(40 / 188)$ & $37 \%(13 / 35)$ & $36 \%(43 / 120)$ & 1.27 & $1.12-1.45$ & 0.000 & 0.000 \\
\hline NYD + K & $7 \%(3 / 42)$ & $23 \%(53 / 234)$ & $36 \%(68 / 188)$ & $29 \%(10 / 35)$ & $28 \%(34 / 120)$ & 1.10 & $0.97-1.25$ & 0.127 & 0.093 \\
\hline YYD + K & $\begin{array}{c}29 \%(12 / \\
42)\end{array}$ & $27 \%(64 / 234)$ & $14 \%(27 / 188)$ & $9 \%(3 / 35)$ & $20 \%(24 / 120)$ & 0.86 & $0.74-1.00$ & 0.041 & 0.022 \\
\hline $\mathrm{YYY}+\mathrm{K}$ & $10 \%(4 / 42)$ & $7 \%(16 / 234)$ & $4 \%(7 / 188)$ & $0 \%(0 / 35)$ & $4 \%(5 / 120)$ & 0.79 & $0.59-1.06$ & 0.110 & 0.079 \\
\hline $\mathrm{NFD}+\mathrm{T}$ & $0 \%(0 / 42)$ & $5 \%(12 / 234)$ & $5 \%(10 / 188)$ & $9 \%(3 / 35)$ & $3 \%(3 / 120)$ & 0.96 & $0.76-1.21$ & 0.732 & 0.746 \\
\hline NYD + T & $7 \%(3 / 42)$ & $5 \%(12 / 234)$ & $8 \%(15 / 188)$ & $6 \%(2 / 35)$ & $8 \%(9 / 120)$ & 1.05 & $0.87-1.26$ & 0.624 & 0.640 \\
\hline YYD + T & $17 \%(7 / 42)$ & $7 \%(17 / 234)$ & $7 \%(14 / 188)$ & $6 \%(2 / 35)$ & $0 \%(0 / 120)$ & 0.59 & $0.41-0.83$ & 0.003 & 0.000 \\
\hline YYY + T & $19 \%(8 / 42)$ & $6 \%(14 / 234)$ & $4 \%(7 / 188)$ & $6 \%(2 / 35)$ & $2 \%(2 / 120)$ & 0.63 & $0.39-1.00$ & 0.050 & 0.003 \\
\hline
\end{tabular}

The haplotypes refers to amino acid positions pfmdr1 N86Y, Y184F, D1246Y and pfcrt K76T. Yearly OR is the Odds Ratio for logistic regression 2006 until 2011 with year included as a continuous covariate. The OR can thus be interpreted as the relative change per year. $\mathrm{N}=$ asparagine, $\mathrm{Y}=$ tyrosine, $\mathrm{F}=$ phenylalanine, $\mathrm{D}=$ aspartic acid, $\mathrm{K}=$ lysine, $\mathrm{T}=$ threonine.

treatment in vivo is significantly associated with the ability to withstand higher lumefantrine concentrations [15]. In this context it is also worth noting that there are studies suggesting that both the artemisinin-derivatives and lumefantrine select for the same molecular markers $[28,29]$. This, together with the recent evidence from Southeast Asia that P. falciparum is able to develop artemisinin tolerance/resistance, is of particular concern as it could result in an additive or even synergistic selection of molecular markers of anti-malarial drug resistance in the parasite population.

It is of note that the blood slide positivity rate in Study 5 was lower (17\%) compared with the mean for all other studies combined (53\%). This may be due to that Study 5 was conducted during October-January, when the malaria transmission is relatively low. However, this did not appear to have influenced the SNP prevalences. Furthermore, it is important to underline that clinical efficacy of artemether-lumefantrine remained high in the study area with PCR-corrected cure rate $>95 \%$ in 2007 [7]. Nevertheless, in an era when the number of malaria patients is slowly declining, standard in vivo trials are increasingly difficult and costly to conduct. In this context, molecular surveillance may play an important role to detect selection of genetic markers associated with ACT tolerance/ resistance in the local $P$. falciparum population over time.

\section{Conclusions}

Increased prevalence of pfmdr1 N86, 184F, D1246 and pfcrt K76 was observed in the parasite population after deployment of artemether-lumefantrine as first-line treatment for uncomplicated malaria. The pfmdrl haplotype NFD increased significantly at the cost of YYY and YYD. The temporal selection of molecular markers associated with artemether-lumefantrine tolerance/resistance may represent an early warning sign of impaired future drug efficacy. This calls for stringent surveillance of artemetherlumefantrine efficacy in Tanzania and emphasizes the importance of molecular surveillance as a complement to standard in vivo trials.

\section{Competing interests}

The authors declare that they have no competing interests.

\section{Authors' contributions}

MM carried out the molecular analysis, participated in the design, coordinated the work and drafted the manuscript. BN and ZP participated in the planning and conduct of the field trials. EL and $\mathrm{AH}$, participated in extraction and genotyping. IJ performed copy number variation analysis. MP assisted in the statistical analysis. PEF, JPG and AB participated in the design of the study and interpretation of results. AM participated in the planning and conduct of the field trials, designed of the study and interpretation of results. All authors critically revised the manuscript and approved the final version of the manuscript.

\section{Acknowledgements}

We would like to thank all patients and their relatives as well as staff members at the Fukayosi Dispensary, Bagamoyo District, Tanzania, for their dedicated participation in the clinical studies. We are also grateful to Richard Mwaisselloh for providing data on blood slide positivity rate. This work was supported by The Swedish Development Cooperation Agency-Department for Research Cooperation (AM: SIDA-SAREC 2009-193 and BN: Bil-Tz 16/9875007059), AM: Swedish Civil Contingencies Agency (MSB) 2010-7991 and MM: Goljes foundation.

\section{Author details}

${ }^{1}$ Malaria Research, Department of Medicine Solna, Karolinska Institutet, Stockholm, Sweden. ${ }^{2}$ Department of Parasitology, Muhimbili University of Health and Allied Sciences, Dar-es-Salaam, Tanzania. ${ }^{3}$ Centre of Molecular and Structural Biomedicine, Institute of Biotechnology and Bioengineering, University of Algarve, Faro, Portugal. ${ }^{4}$ Departamento de Parasitología, Escuela de Microbiología, Facultad de Ciencias Universidad Nacional Autónoma de Honduras (UNAH), Tegucigalpa, Honduras. ${ }^{5}$ Centre for Applied Biostatistics, Sahlgrenska Academy, University of Gothenburg, Gothenburg, Sweden. ${ }^{6}$ Drug resistance Unit, Division of Pharmacogenetics, Department of Physiology and Pharmacology, Karolinska Institutet, Stockholm, Sweden. ${ }^{7}$ Department of Biological Sciences, The Harpur College of Arts and Sciences, Binghamton University, Binghamton, NY, USA. ${ }^{8}$ Division of Global Health (IHCAR), Department of Public Health Sciences, Karolinska Institutet, Stockholm, Sweden

Received: 18 November 2012 Accepted: 9 March 2013

Published: 18 March 2013 


\section{References}

1. Amaratunga C, Sreng S, Suon S, Phelps ES, Stepniewska K, Lim P, Zhou C, Mao S, Anderson JM, Lindegardh N, Jiang H, Song J, Su XZ, White NJ, Dondorp AM, Anderson TJ, Fay MP, Mu J, Duong S, Fairhurst RM: Artemisinin-resistant Plasmodium falciparum in Pursat province, western Cambodia: a parasite clearance rate study. Lancet Infect Dis 2012, 12:851-858

2. Dondorp AM, Nosten F, Yi P, Das D, Phyo AP, Tarning J, Lwin KM, Ariey F, Hanpithakpong W, Lee SJ, Ringwald P, Silamut K, Imwong M, Chotivanich K, Lim P, Herdman T, An SS, Yeung S, Singhasivanon P, Day NP, Lindegardh N, Socheat $D$, White $\mathrm{NJ}$ : Artemisinin resistance in Plasmodium falciparum malaria. N Engl J Med 2009, 361:455-467.

3. Noedl H, Se Y, Schaecher K, Smith BL, Socheat D, Fukuda MM: Evidence of artemisinin-resistant malaria in western Cambodia. N Engl J Med 2008 359:2619-2620.

4. Borrmann S, Sasi P, Mwai L, Bashraheil M, Abdallah A, Muriithi S, Fruhauf $H_{\text {, }}$ Schaub B, Pfeil J, Peshu J, Hanpithakpong W, Rippert A, Juma E, Tsofa B, Mosobo M, Lowe B, Osier F, Fegan G, Lindegårdh N, Nzila A, Peshu N, Mackinnon M, Marsh K: Declining responsiveness of Plasmodium falciparum infections to artemisinin-based combination treatments on the Kenyan coast. PLoS One 2011, 6:e26005.

5. Mårtensson A, Stromberg J, Sisowath C, Msellem MI, Gil JP, Montgomery SM, Olliaro P, Ali AS, Björkman A: Efficacy of artesunate plus amodiaquine versus that of artemether-lumefantrine for the treatment of uncomplicated childhood Plasmodium falciparum malaria in Zanzibar, Tanzania. Clin Infect 2005, 41:1079-1086.

6. Mårtensson A, Ngasala B, Ursing J, Isabel Veiga M, Wiklund L, Membi C, Montgomery SM, Premji Z, Farnert A, Björkman A: Influence of consecutive-day blood sampling on polymerase chain reaction-adjusted parasitological cure rates in an antimalarial-drug trial conducted in Tanzania. J Infect Dis 2007, 195:597-601.

7. Ngasala BE, Malmberg M, Carlsson AM, Ferreira PE, Petzold MG, Blessborn D, Bergqvist $Y$, Gil JP, Premji Z, Björkman A, Mårtensson A: Efficacy and effectiveness of artemether-lumefantrine after initial and repeated treatment in children $<5$ years of age with acute uncomplicated Plasmodium falciparum malaria in rural Tanzania: a randomized trial. Clin Infect Dis 2011, 52:873-882.

8. Sisowath C, Stromberg J, Mårtensson A, Msellem M, Obondo C, Björkman A, Gil JP: In vivo selection of Plasmodium falciparum pfmdr1 $86 \mathrm{~N}$ coding alleles by artemether-lumefantrine (Coartem). J Infect Dis 2005, 191:1014-1017.

9. Sisowath C, Ferreira PE, Bustamante LY, Dahlstrom S, Mårtensson A, Björkman A, Krishna S, Gil JP: The role of pfmdr1 in Plasmodium falciparum tolerance to artemether-lumefantrine in Africa. Trop Med Int Health 2007, 12:736-742.

10. Sisowath C, Petersen I, Veiga MI, Mårtensson A, Premji Z, Björkman A, Fidock DA, Gil JP: In vivo selection of Plasmodium falciparum parasites carrying the chloroquine-susceptible pfcrt K76 allele after treatment with artemether-lumefantrine in Africa. J Infect Dis 2009, 199:750-757.

11. Carlsson AM, Ngasala BE, Dahlstrom S, Membi C, Veiga IM, Rombo L, Abdulla S, Premji Z, Gil JP, Björkman A, Mårtensson A: Plasmodium falciparum population dynamics during the early phase of anti-malarial drug treatment in Tanzanian children with acute uncomplicated malaria. Malar J 2011, 10:380.

12. Veiga MI, Ferreira PE, Björkman A, Gil JP: Multiplex PCR-RFLP methods for pfcrt, pfmdr1 and pfdhfr mutations in Plasmodium falciparum. Mol Cell Probes 2006, 20:100-104.

13. Holmgren G, Hamrin J, Svard J, Mårtensson A, Gil JP, Björkman A: Selection of pfmdr 1 mutations after amodiaquine monotherapy and amodiaquine plus artemisinin combination therapy in East Africa. Infect Genet Evol 2007, 7:562-569

14. Veiga MI, Ferreira PE, Jornhagen $L$, Malmberg $M$, Kone $A$, Schmidt BA, Petzold M, Björkman A, Nosten F, Gil JP: Novel polymorphisms in Plasmodium falciparum $\mathrm{ABC}$ transporter genes are associated with major ACT antimalarial drug resistance. PLoS One 2011, 6:e20212.

15. Malmberg M, Ferreira PE, Tarning J, Ursing J, Ngasala B, Björkman A, Mårtensson A, Gil JP: Plasmodium falciparum drug resistance phenotype as assessed by patient antimalarial drug levels and its association with pfmdr1 polymorphisms. J Infect Dis 2013, 207:842-847.

16. Price RN, Uhlemann AC, Brockman A, McGready R, Ashley E, Phaipun L, Patel R, Laing K, Looareesuwan S, White NJ, Nosten F, Krishna S: Mefloquine resistance in Plasmodium falciparum and increased pfmdr1 gene copy number. Lancet 2004, 364:438-447.

17. ClinicalTrials.gov. http://www.clinicaltrials.gov/,

18. ISRCTN. http://www.isrctn.org.

19. Lekana-Douki JB, Dinzouna Boutamba SD, Zatra R, Zang Edou SE, Ekomy H, Bisvigou U, Toure-Ndouo FS: Increased prevalence of the Plasmodium falciparum Pfmdr1 86N genotype among field isolates from Franceville, Gabon after replacement of chloroquine by artemether-lumefantrine and artesunate-mefloquine. Infect Genet Evol 2011, 11:512-517.

20. Mang'era CM, Mbai FN, Omedo IA, Mireji PO, Omar SA: Changes in genotypes of Plasmodium falciparum human malaria parasite following withdrawal of chloroquine in Tiwi, Kenya. Acta Trop 2012, 123:202-207.

21. Raman J, Mauff K, Muianga P, Mussa A, Maharaj R, Barnes Kl: Five years of antimalarial resistance marker surveillance in Gaza Province,

Mozambique, following artemisinin-based combination therapy roll out PLoS One 2011, 6:e25992.

22. Thomsen $\Pi$, Ishengoma DS, Mmbando BP, Lusingu JP, Vestergaard LS, Theander TG, Lemnge MM, Bygbjerg IC, Alifrangis M: Prevalence of single nucleotide polymorphisms in the Plasmodium falciparum multidrug resistance gene (Pfmdr-1) in Korogwe District in Tanzania before and after introduction of artemisinin-based combination therapy. Am J Trop Med Hyg 2011, 85:979-983.

23. Thomsen TT, Madsen LB, Hansson HH, Tomas EV, Charlwood D, Bygbjerg IC, Alifrangis M: Rapid selection of Plasmodium falciparum chloroquine resistance transporter gene and multidrug resistance gene- 1 haplotypes associated with past chloroquine and present artemether-lumefantrine use in Inhambane District, Southern Mozambique. Am J Trop Med Hyg 2013, 88:536-541.

24. Laufer MK, Takala-Harrison S, Dzinjalamala FK, Stine OC, Taylor TE, Plowe CV: Return of chloroquine-susceptible falciparum malaria in Malawi was a reexpansion of diverse susceptible parasites. I Infect Dis 2010, 202:801-808.

25. Babiker HA, Hastings IM, Swedberg G: Impaired fitness of drug-resistant malaria parasites: evidence and implication on drug-deployment policies. Expert Rev Anti Infect Ther 2009, 7:581-593.

26. Ferreira PE, Culleton R: Dynamics of Plasmodium falciparum selection after artemether-lumefantrine treatment in Africa. J Infect Dis 2012, 205:1473-1475. author reply 1475-1476.

27. Mwai L, Kiara SM, Abdirahman A, Pole L, Rippert A, Diriye A, Bull P, Marsh K, Borrmann S, Nzila A: In vitro activities of piperaquine, lumefantrine, and dihydroartemisinin in Kenyan Plasmodium falciparum isolates and polymorphisms in pfcrt and pfmdr1. Antimicrob Agents Chemother 2009, 53:5069-5073.

28. Duraisingh MT, Jones $P$, Sambou I, von Seidlein L, Pinder M, Warhurst DC: The tyrosine- 86 allele of the pfmdr1 gene of Plasmodium falciparum is associated with increased sensitivity to the anti-malarials mefloquine and artemisinin. Mol Biochem Parasitol 2000, 108:13-23.

29. Reed MB, Saliba KJ, Caruana SR, Kirk K, Cowman AF: Pgh1 modulates sensitivity and resistance to multiple antimalarials in Plasmodium falciparum. Nature 2000, 403:906-909.

doi:10.1186/1475-2875-12-103

Cite this article as: Malmberg et al:: Temporal trends of molecular markers associated with artemether-lumefantrine tolerance/resistance in Bagamoyo district, Tanzania. Malaria Journal 2013 12:103.

\section{Submit your next manuscript to BioMed Central and take full advantage of:}

- Convenient online submission

- Thorough peer review

- No space constraints or color figure charges

- Immediate publication on acceptance

- Inclusion in PubMed, CAS, Scopus and Google Scholar

- Research which is freely available for redistribution 